\title{
Antiaging gene Klotho regulates epithelial-mesenchymal transition and increases sensitivity to pemetrexed by inducing lipocalin-2 expression
}

\author{
KYOSHIRO TAKEGAHARA, JITSUO USUDA, TATSUYA INOUE, \\ TAKUMI SONOKAWA, TAKUMA MATSUI and MITSUO MATSUMOTO \\ Department of Thoracic Surgery, Nippon Medical School, Tokyo 113-8603, Japan
}

Received May 20,2020; Accepted November 11, 2020

DOI: $10.3892 / \mathrm{ol} .2021 .12679$

\begin{abstract}
Epithelial-mesenchymal transition (EMT) is considered to serve an important role in the metastatic/invasive ability of cancer cells, in the acquisition of drug resistance, and in metabolic reprogramming. In the present study, it was hypothesized that the Klotho gene is involved in the metastatic/invasive ability of lung cancer. We previously reported an association between Klotho expression and overall survival in patients with small cell lung cancer and large cell neuroendocrine cancer. We also found that Klotho expression was associated with EMT-related molecules in lung squamous cell carcinoma. The present study aimed to analyze the function of the Klotho gene and to elucidate its relevance to the regulation of the EMT. For this purpose, GFP-Klotho plasmids were transfected into lung adenocarcinoma cells (A549) and cell lines with stable expression (A549/KL-1 and A549/KL-2) were established. A549/KL-1 cells expressed higher levels of Klotho protein by western blot analysis compared with A549/KL-2 cells. In western blotting of A549 and A549/KL-1 cells, the expression of the mesenchymal marker $\mathrm{N}$-cadherin was found to be completely inhibited in A549/KL-1 cells suggesting that Klotho expression may regulate the EMT in cancer cells via the inhibition of $\mathrm{N}$-cadherin. The results of the sensitivity tests demonstrated that A549/KL-1 cells were significantly more sensitive to pemetrexed compared with A549 cells ( IC $_{50}$ A549/KL-1 vs. A549 cells, $0.1 \mu \mathrm{M}$ vs. $0.7 \mu \mathrm{M}$ ). The results of the microarray analysis demonstrated that a very high level of lipocalin-2 (LCN2) expression was induced in the A549/KL-1 cells. Klotho overexpression completely suppressed the expression of mesenchymal markers, such as N-cadherin and Snaill (Snail).
\end{abstract}

Correspondence to: Dr Jitsuo Usuda, Department of Thoracic Surgery, Nippon Medical School, 1-1-5 Sendagi, Tokyo 113-8603, Japan

E-mail: jusuda@nms.ac.jp

Key words: epithelial-mesenchymal transition, Klotho, lipocalin-2, pemetrexed, lung cancer
The results of the present study suggested that there may be a new mechanism of action for the antitumor effects of pemetrexed, namely, LCN2-mediated modulation of N-cadherin expression. Klotho expression during cancer treatment has great potential as a predictor for efficacy of pemetrexed and as a factor in the selection of personalized medicine for postoperative adjuvant chemotherapy.

\section{Introduction}

Lung cancer is the leading cause of cancer-related death in the world $(1,2)$. The majority of these cancers are non-small cell lung cancers, of which adenocarcinoma is the most common histological subtype (1). However, treatment outcomes have been less than satisfactory. To improve the postoperative outcome of lung cancer, effective chemotherapy regimens need to be established for each individual case and individualized treatment practices need to be implemented. In recent years, new molecularly targeted drugs and immune checkpoint inhibitors have been developed and treatment strategies, especially for non-small cell lung cancer (NSCLC), have been improved using personalized medicine (2-4).

Epithelial-mesenchymal transition (EMT) is considered to serve an important role in the metastatic/invasive ability of cancer cells $(5,6)$. As the EMT progresses, epithelial cells lose their cell-cell adhesion property and cell polarity and assume the phenotype of highly motile mesenchymal cells (5). E-cadherin is a typical adhesion molecule that forms the adhesion junctions between epithelial cells, and its expression is suppressed as EMT traits are acquired $(6,7)$. In addition, increases in the expressions of the mesenchymal markers $\mathrm{N}$-cadherin (a mesenchymal cadherin), vimentin (a cytoskeletal protein) and fibronectin (an extracellular matrix molecule) are observed during the EMT (8). In particular, among the cell adhesion molecules, the expression of the epithelial cadherin E-cadherin decreases during EMT, whereas the expression of the mesenchymal cadherin N-cadherin increases; this phenomenon is known as the cadherin switch and is thought to serve an important role in cancer cell invasion and progression $(9,10)$. Since apoptosis resistance and stem cell properties also become manifest at the same time, EMT is considered to be a factor that generates diversity among cancer cells (11-14). 
In addition, EMT causes cancer cells to become resistant to natural killer cells (15), and the induction of the EMT in cancer cells through the administration of anticancer drugs can lead to drug resistance (16-18). Thus, elucidating cancer diversity, resistance acquisition, and the related EMT mechanism could lead to new cancer treatment methods.

The Klotho gene was originally discovered during the creation of a hypertensive mouse model (19). Mice with genetic mutations in the Klotho gene exhibit a human-like aging-related syndrome and develop multiple disorders, including hypogonadism, ectopic calcification, osteoporosis, skin atrophy and pulmonary emphysema (20). Transgenic mice overexpressing Klotho have an extended life span that is $30 \%$ longer in males and $20 \%$ longer in females compared with wild-type controls (21). The Klotho gene is associated not only with antiaging, but also with cancer growth and invasion, including in breast, pancreatic, ovarian, lung, colorectal cancer and melanoma (22). Klotho functions as a tumor suppressor by inhibiting insulin/insulin growth factor 1, p53/p21 and Wnt signaling $(23,24)$. The silencing of Klotho gene expression is mainly mediated through promoter hypermethylation and histone deacetylation in cancer (25). The Klotho gene reportedly acts as a tumor suppressor gene in breast cancer and suppresses proliferation and induces apoptosis in lung adenocarcinoma cells $(26,27)$.

We hypothesized that the Klotho gene is also involved in the metastatic/invasive ability of lung cancer. We previously reported an association between Klotho expression and overall survival in patients with small cell lung cancer (SCLC) and large cell neuroendocrine cancer (LCNEC) $(28,29)$. Klotho expression has also been shown to be an important postoperative prognostic factor in patients with SCLC and LCNEC $(28,29)$. We also found that Klotho expression was associated with EMT-related molecules in lung squamous cell carcinoma (30)

The present study focused on the association between the Klotho gene and cancer metastasis in lung adenocarcinoma. In particular, the present study aimed to analyze the function of the Klotho gene to elucidate its relevance to the regulation of the EMT which is part of the metastasis process. The possibility of a new cancer treatment based on the Klotho gene using drugs and a growth-inhibition assay was also assessed. In particular, the present study focused on the use of pemetrexed, an antifolate drug (31). Studies have suggested that blocking the EMT pathway could eliminate resistance to antifolate chloride therapy in lung cancer (32). The findings of the present study that investigate the link between pemetrexed, EMT and the Klotho gene could be a stepping stone to new lung cancer therapies.

\section{Materials and methods}

Cell culture and transfection. A549 a human lung adenocarcinoma cell line was maintained in Dulbecco's modified Eagle's medium (DMEM; cat. no. D6429; Millipore Sigma) supplemented with $0.1 \%$ sodium bicarbonate, L-glutamine, sodium pyruvate, $10 \%$ heat-inactivated fetal bovine serum (FBS; cat. no. F2442; Millipore Sigma), and penicillin $(100 \mathrm{U} / \mathrm{ml})$ in a humidified atmosphere of $5 \% \mathrm{CO}_{2}$ at $37^{\circ} \mathrm{C}$. GFP-Klotho plasmids were transfected into A549 cells using the Lipofectamine $3000{ }^{\circledR}$ transfection reagent according to the manufacturer's instructions (Invitrogen; Thermo Fisher Scientific Inc.). Cells were transfected with $2 \mu \mathrm{g}$ of plasmid DNA using the transfection reagent, and were incubated for $2 \mathrm{~h}$ in a humidified atmosphere of $5 \% \mathrm{CO}_{2}$ at $37^{\circ} \mathrm{C}$. The cells were washed and medium including FBS added $(30,33)$. The GFP-Klotho plasmid or a GFP vector was transfected into the A549 cells, and $24 \mathrm{~h}$ later the cells were pelleted (almost $1 \mathrm{mg}$ ) by centrifugation at $1,500 \mathrm{x}$ g for $10 \mathrm{~min}$ and resuspended in PBS to a final density of $\sim 2.9 \times 10^{6}$ cells $/ \mathrm{ml}$ and the suspension was then filtered through a nylon membrane to remove cell aggregates (30). The GFP-positive cells were sorted using flow cytometry and a FACSCanto II (BD Biosciences) with the activation set at $488 \mathrm{~nm}$ and fluorescence emission monitoring at $508 \mathrm{~nm}$ (GFP). The data acquisition and analysis were performed using FlowJo ${ }^{\mathrm{TM}}$ v.10.7 software (TreeStar Inc.). At least 10,000 events were collected for each analysis. Dead cells and debris were eliminated using the forward-scatter and side-scatter parameters, and the remaining cells were sorted into GFP-positive and GFP-negative populations.

Isolation of clones expressing Klotho. Following GFP-Klotho transfection, the GFP-positive cells were cultured with $0.1 \%$ sodium bicarbonate, L-glutamine, sodium pyruvate, and $10 \%$ heat-inactivated fetal bovine serum (FBS), penicillin $(100 \mathrm{U} / \mathrm{ml})$ in a humidified atmosphere of $5 \% \mathrm{CO}_{2}$ at $37^{\circ} \mathrm{C}$ for 2-3 weeks and the colonies were harvested. A single clone was obtained using a limiting dilution method (34). Several colonies were checked for Klotho expression using western blotting and two stably overexpressing Klotho cell lines: A549/KL-1 and A549/KL-2 were established.

Western blotting. A549, A549/KL-1, and A549/KL-2 cells were harvested by centrifugation at $1,500 \mathrm{x} \mathrm{g}$ for $10 \mathrm{~min}$ and washed twice with ice-cold PBS; the cell pellets were then incubated in a lysis buffer $(50 \mathrm{mM}$ Tris- $\mathrm{HCl}, \mathrm{pH} 7.6$, $120 \mathrm{mM} \mathrm{NaCl}, 1 \%$ Triton X-100, 0.2\% sodium-deoxycholate and a protease inhibitor). After cooling the lysates on ice for $10 \mathrm{~min}$, they were centrifuged at $14,000 \mathrm{x} \mathrm{g}$ for $30 \mathrm{~min}$. For protein determination, a bicinchoninic Acid (BCA) kit was used (Sigma-Aldrich; Merck KGaA). Each sample of $10 \mu \mathrm{g}$ of total protein was separated using 7.5\% SDS-PAGE gels and transferred to polyvinylidene difluoride membranes. After blocking with 5\% skimmed milk at room temperature for $1 \mathrm{~h}$, the membranes were incubated for $1 \mathrm{~h}$ at room temperature with the following antibodies: rat anti-human Klotho monoclonal antibody (1:500; clone KM2076; cat. no. KO603; Trans Genic Inc.), rabbit anti-human E-cadherin monoclonal antibody (1:1,000; clone 24E10; cat. no. 3195), rabbit anti-human $\mathrm{N}$-cadherin monoclonal antibody $(1: 1,000$; clone D4R1H; cat. no. 13116), rabbit anti-human vimentin monoclonal antibody (1:1,000; clone D21H3; cat. no. 5741), or rabbit anti-human Snail monoclonal antibody (1:500; clone C15D3; cat. no. 3879) (all from Cell Signaling Technology, Inc.) or anti-TS antibody (clone 8F1; cat. no. 35-5800; Zymed; Thermo Fisher Scientific Inc.) $(33,35)$. After rinsing with PBS containing $0.1 \%$ (v/v) Triton X-100, the membranes were incubated with goat anti-rat immunoglobulin-G ( $\mathrm{IgG})$-conjugated horseradish peroxidase (HRP) (1:10,000 dilution; cat. no. 65-9520, Thermo Fisher Scientific Inc.) for the anti-Klotho antibody or 
with goat anti-rabbit IgG conjugated HRP (1:2,000 dilution; cat. no. 31460; Thermo Fisher Scientific Inc.) for the other antibodies for $1 \mathrm{~h}$ at room temperature. Blots were probed with $\beta$-actin (1:1,000 dilution; cat. no. 4967; Cell Signaling Technology, Inc.) as a loading control. The membranes were washed and developed with western blotting enhanced chemiluminescence detection reagents (Bio-Rad Laboratories Inc.) (36). The western blotting results were confirmed in three independent experiments.

Drugs and growth-inhibition assay. Afatinib, ceritinib, gefitinib and osimertinib were purchased from Selleck Chemicals. Carboplatin, cisplatin, docetaxel and paclitaxel were purchased from Sigma-Aldrich; Merck KGaA. Pemetrexed was purchased from Toronto Research Chemicals $(37,38)$. A549 and A549/KL-1 cells (2,000 cells/well) were seeded into 96-well plates, and the drugs were added in increasing concentrations $(0,0.01,0.1,1,10$ and $100 \mu \mathrm{M})$ at room temperature. The half maximal inhibitory concentration $\left(\mathrm{IC}_{50}\right)$ value was defined as the concentration of an anticancer agent required to reduce growth by $50 \%$. The corrected absorbance of each sample compared with that of the untreated control was calculated by MTT assay using the absorbance wavelength at $570 \mathrm{~nm}$.

Determination of cell viability. Sensitivity tests (MTT assays) for various anticancer agents including afatinib, carboplatin, ceritinib, cisplatin, docetaxel, gefitinib, osimertinib, paclitaxel and pemetrexed using A549 cells and A549/KL-1 cells were performed (39). DMSO was used to dissolve the purple formazan and measured by the wavelength at $570 \mathrm{~nm}$.

cDNA microarray analysis. Gene expression in lung cancer cells, A549 cells and A549/KL-1 cells, were analyzed using a cDNA microarray. mRNA was extracted and purified using the mammalian total RNA Miniprep kit (cat. no. RTN10; Sigama-Aldrich Inc.). A commercially available cDNA microarray, the Human Genome U133 plus 2.0 array (cat. no. 900470, Thermo Fisher Scientific Inc.), on which 47,000 gene probes had been arrayed was used. Gene expression data was analyzed using Transcriptome Analysis Console (TAC) software v.3.1 (Applied Biosystems). Significantly modulated genes were defined as $\log _{2}$ fold change $(\mathrm{FC})>2$ and adjusted $\mathrm{P}$-value $<0.05$.

Statistical analysis. Results of the experiments were presented as the mean $\pm \mathrm{SD}$ or the mean of independent triplicate experiments and were analyzed using the Student's unpaired t-test. The statistical analyses were two-tailed and were performed using Microsoft Excel (Microsoft Corporation). P $<0.05$ was considered to indicate a statistically significant difference.

\section{Results}

Expression of Klotho in A549 and stably overexpressing Klotho cell lines. To elucidate the mechanism of action of the Klotho gene, GFP-Klotho plasmids were transfected into the human lung adenocarcinoma cell line A549 and two stable cell lines were established: A549/KL-1 and A549/KL-2. In a western blot analysis these cell lines had high expression

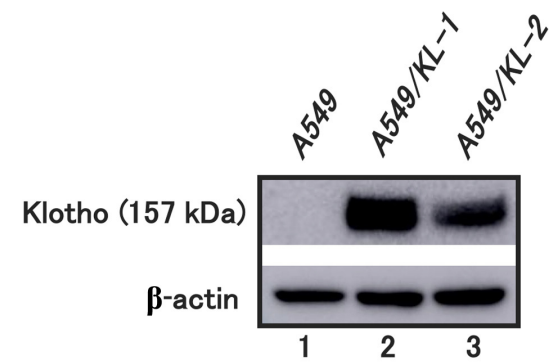

Figure 1. Western blot analysis using anti-Klotho antibody for A549 cells and Klotho over expressing: A549/Klotho-1 and A549/Klotho-2 cells. Lanes 1-3 present the parent A549 cells, A549/Klotho-1 (high Klotho level), and A549/Klotho-2 cells (slightly high level). KL, Klotho.

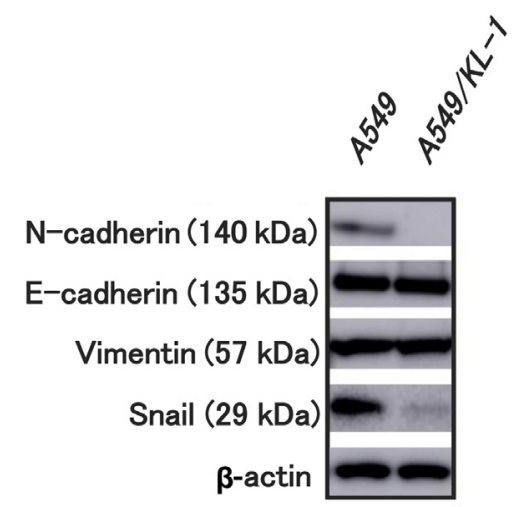

Figure 2. Western blot analysis for A549 cells and A549/Klotho-1 cells using anti-E-cadherin antibody, anti-N-cadherin antibody, anti-snail antibody and anti-vimentin antibody. KL, Klotho; Snail, Snail 1.

levels of Klotho protein, while the parental A549 cells did not express Klotho protein at all. The A549/KL-1 cells expressed higher levels of Klotho protein compared with A549/KL-2 cells (Fig. 1).

Expression of the expression of EMT marker proteins. Subsequently, immunoblotting was to determine whether Klotho expression affected the expression of EMT marker proteins (Fig. 2). Further experimentation was performed using the A549/KL-1 cell line and not A549/KL-2. The expression of the mesenchymal marker N-cadherin was completely inhibited in the Klotho-overexpressing A549/KL-1 cells compared with the parental A549 cells and Klotho overexpression did not affect the regulation of other mesenchymal markers including vimentin or the epithelial marker E-cadherin (Fig. 2). Interestingly, Klotho-overexpression also appeared to have downregulated the expression of the mesenchymal marker Snail in A549/KL-1 cells compared with the parental A549 cells (Fig. 2).

Klotho expression is related to the sensitivity of cancer cells to pemetrexed. To evaluate the association between Klotho expression and the antitumor effect of various anticancer agents, sensitivity tests were performed to evaluate the growth inhibitory effects on both A549 cells and A549/KL-1 cells, which have high levels of Klotho expression (Table I). The cell survival curves for A549 and A549/KL-1 exposed to 


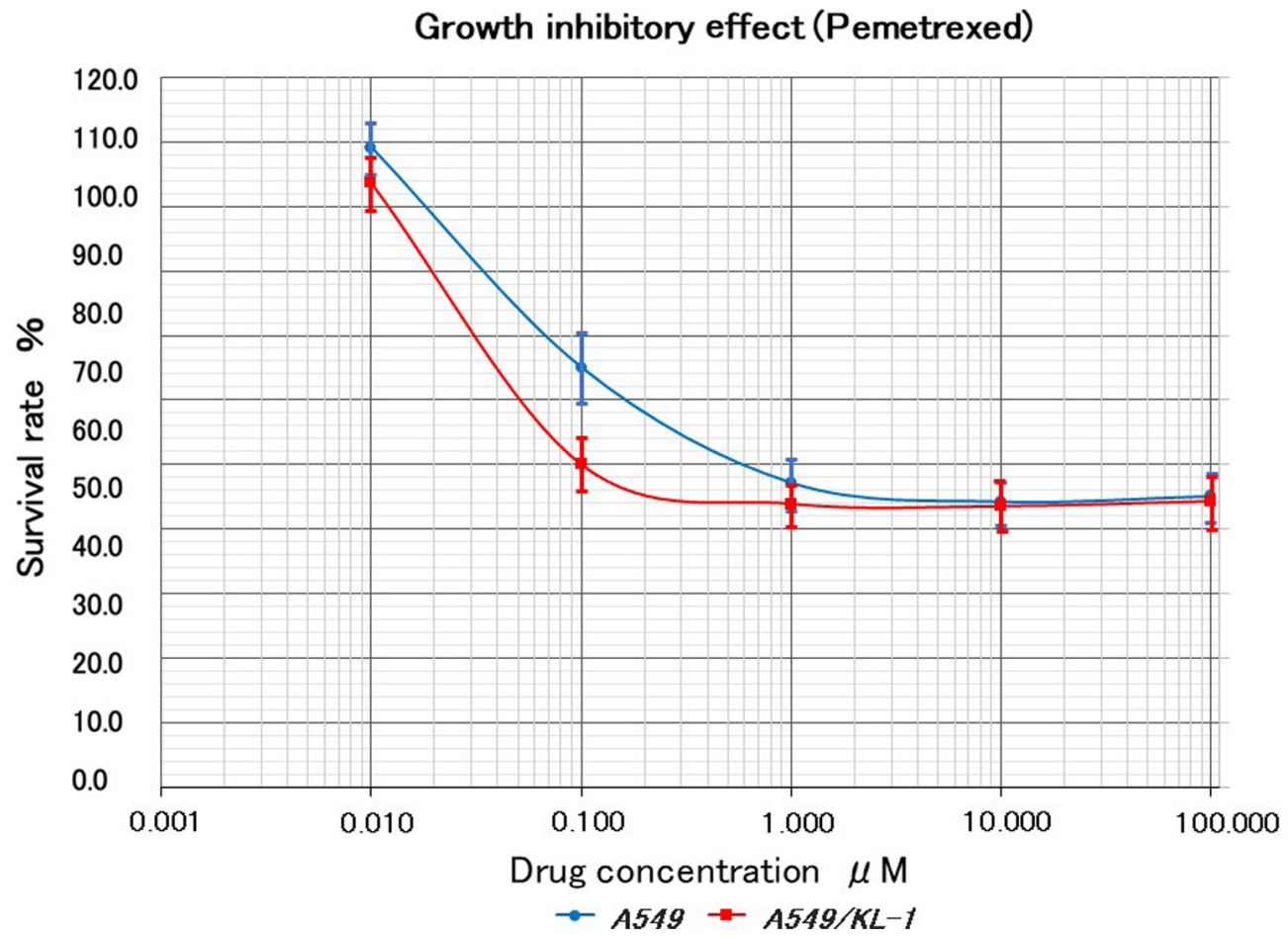

Figure 3. Survival curves for A549 and A549/KL-1 exposed to pemetrexed. The survival curve of A549 cells is presented in blue and A549/KL-1 is presented in red. Values are the means of triplicate experiments; error bars indicate SD. KL, Klotho.

Table I. IC 50 by MTT assay for A549 cells and A549/KL-1 cells using various anticancer agents.

\begin{tabular}{lrrc}
\hline $\mathrm{IC}_{50}$ & A549 & A549/KL-1 & P-value \\
\hline Afatinib & 2.1 & 3.1 & 0.155 \\
Carboplatin & 128.0 & 242.0 & $<0.001$ \\
Cisplatin & 4.9 & 11.8 & $<0.001$ \\
Ceritinib & 2.7 & 2.7 & 1 \\
Docetaxel & 3.9 & 4.7 & 0.196 \\
Gefitinib & 26.0 & 28.0 & 0.196 \\
Osimertinib & 2.2 & 2.7 & 0.288 \\
Paclitaxel & 9.0 & 10.0 & 0.109 \\
Pemetrexed & 0.7 & 0.1 & $<0.001$ \\
\hline
\end{tabular}

Concentrations of afatinib, carboplatin, ceritinib, cisplatin, gefitinib, osimertinib, and pemetrexed are in $\mu \mathrm{M}$ and the concentrations of docetaxel and paclitaxel are in $\mathrm{nM}$.

pemetrexed are shown in Fig. 3. Pemetrexed caused growth inhibition of A549/KL-1 at lower concentrations of pemetrexed compared with A549 (Fig. 3). The A549/KL-1 cells were considerably more sensitive to pemetrexed compared with the A549 cells, with $\mathrm{IC}_{50}$ values of $0.1 \mu \mathrm{M}$ in the A549/KL-1 cells and $0.7 \mu \mathrm{M}$ in the $\mathrm{A} 549$ cells $(\mathrm{P}<0.001$; Table I). However, no increased sensitivity of the A549 and A549/KL-1 cells was seen to the other anticancer agents tested, including the moleculartargeted drugs afatinib, ceritinib, gefitinib, and osimertinib and the cytotoxic drugs cisplatin, carboplatin, paclitaxel and docetaxel (Table I) (40). These results indicated that Klotho overexpression increased the sensitivity to pemetrexed,

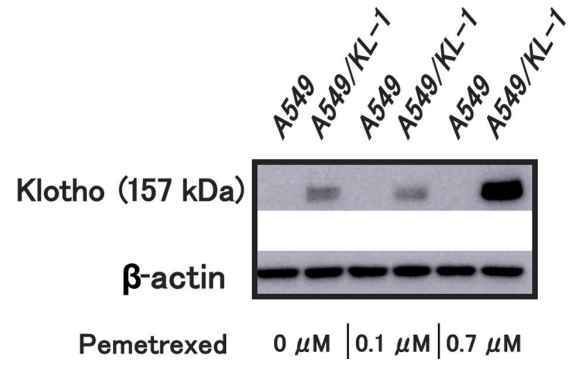

Figure 4. Western blot analysis for A549 cells and A549/KL-1 cells with various doses of pemetrexed $(0,0.1$ and $0.7 \mu \mathrm{M})$ using anti-Klotho antibody. KL, Klotho.

which is a multi-target antifolate that is active against various malignant tumors (31). There was a significant difference of $\mathrm{IC}_{50}$ between A549 cells and A549/KL-1 cells in sensitivity to pemetrexed, but not the other anticancer agents (Table I). However, the mechanism through which Klotho expression affected the antitumor effect of pemetrexed was unclear, so next the expression of Klotho and EMT-related proteins after pemetrexed exposure were investigated. Notably, when A549 and A549/KL-1 cells were exposed to various doses of pemetrexed $(0,0.1$ and $0.7 \mu \mathrm{M})$, Klotho expression increased in the A549/KL-1 cells in a dose-dependent manner, but Klotho expression was not observed in the A549 cells (Fig. 4). These findings suggest that Klotho expression is related to the sensitivity of cancer cells to pemetrexed.

Klotho expression strongly suppresses $N$-cadherin expression. $\mathrm{N}$-cadherin was completely repressed in A549/KL-1 cells compared with the parental cell line, regardless of 

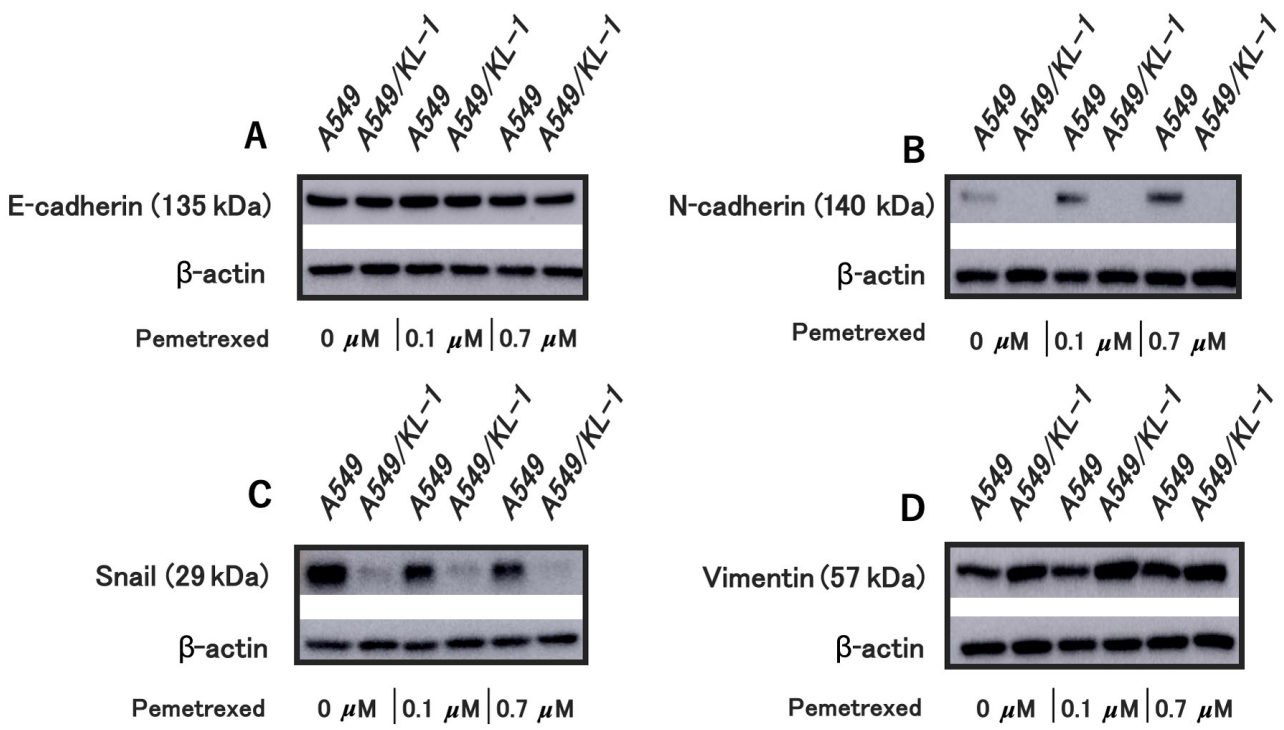

Figure 5. Western blot analysis for A549 cells and A549/Klotho-1 cells treated with various doses of pemetrexed ( $0,0.1$, and $0.7 \mu \mathrm{M})$ using (A) anti-E-cadherin antibody (B) anti-N-cadherin antibody (C) anti-snail antibody and (D) anti-vimentin antibody. KL, Klotho.

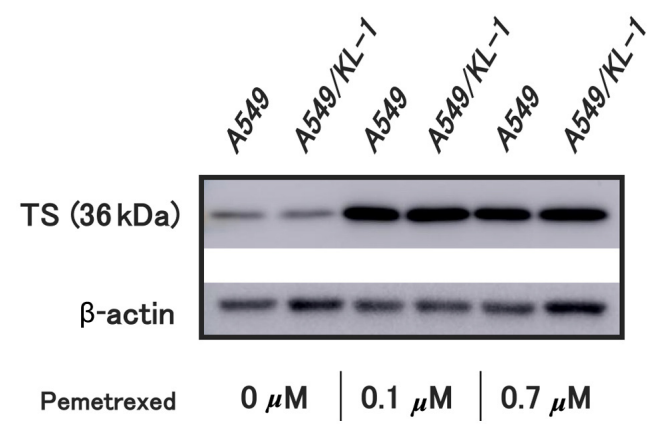

Figure 6. Western blot analysis for A549 cells and A549/Klotho-1 cells treated with various doses of pemetrexed $(0,0.1$ and $0.7 \mu \mathrm{M})$ using anti-TS antibody. KL, Klotho; TS, thymidylate synthase.

pemetrexed concentration, but no difference was observed in other skin-mesenchymal transition-related proteins, such as E-cadherin and vimentin (Fig.5).In A549/KL-1 cells, compared to the parental cell line, Snail expression was slightly reduced by pemetrexed exposure (Fig. 5). Thymidylate synthase (TS) is a target of antifolate drug expression (41). Pemetrexed is a novel antifolate that inhibits several folate-dependent enzymes in addition to TS (31). However, TS expression was slightly increased by pemetrexed exposure, but no difference in TS was observed between the A549 and A549/KL-1 cells (Fig. 6). In A549/KL-1, N-cadherin expression was completely suppressed and $\mathrm{N}$-cadherin was not expressed when the cells were exposed to pemetrexed (Figs. 2 and 5). Hence, Klotho expression strongly suppressed $\mathrm{N}$-cadherin expression.

Klotho gene expression may play a significant role in the regulation of $L C N 2$. To further assess whether Klotho transfection affects host gene expression, microarray analysis was performed to study host genes with differential expression in A549 and A549/KL-1 cells. The top 30 genes with high-fold change values were assessed and the results demonstrated that the expression of EMT-related genes [discoidin I-like domain-containing protein 3 (EDIL3), pentraxin-3 (PTX3), fibrillin-2 (FBN2), interleukin-6 (IL-6)] $(42,43)$ and genes related to pemetrexed [dihydropyrimidine dehydrogenase (DPYD), lipocalin-2 (LCN2)] (44) was upregulated by the introduction of the Klotho gene (Fig. 7). Downregulated genes were also evaluated, but there were no genes that appeared to be involved in EMT or in the suppression of cadherin (data not shown). These results suggested that Klotho gene expression may play a significant role in the regulation of LCN2.

\section{Discussion}

We previously reported that the overexpression of Klotho almost completely suppressed $\mathrm{N}$-cadherin expression using a transient model (30), but the mechanism responsible for the regulation of the EMT by N-cadherin remained unknown. In the present study, the A549/KL-1 cell line with stable Klotho overexpression was established. It was reported that Klotho inhibited TGF- $\beta 1$-induced EMT responses $(45,46)$. Also, it was demonstrated that Klotho is capable of inhibiting the activation of the Wnt signaling pathway, which inhibits glycogen synthase kinase-3 $\beta(47,48)$. Based on the above findings, it was speculated that Klotho serves a critical role as a suppressor of $\mathrm{N}$-cadherin expression by inhibiting Wnt and TGF- $\beta 1$ signaling.

The results of the present study demonstrated that the expression of EMT-related genes (EDIL3, PTX3, FBN2 and IL-6) and genes related to pemetrexed (DPYD, lipocalin-2 (LCN2)] was upregulated by the introduction of the Klotho gene. In the present study, LCN2 was focused on among the upregulated genes, which has been reported to be associated with EMT and pemetrexed. LCN2 belongs to the lipocalin protein family and can exist as a $25-\mathrm{kDa}$ monomer or a 46-kDa disulfide-linked homodimer (44). LCN2 reportedly suppresses cellular invasion and metastases and blocks EMT (49). Wang et al (50) demonstrated that LCN2 negatively modulates EMT and suppresses $\mathrm{N}$-cadherin expression 


\section{Fold change $(\log 2)$}

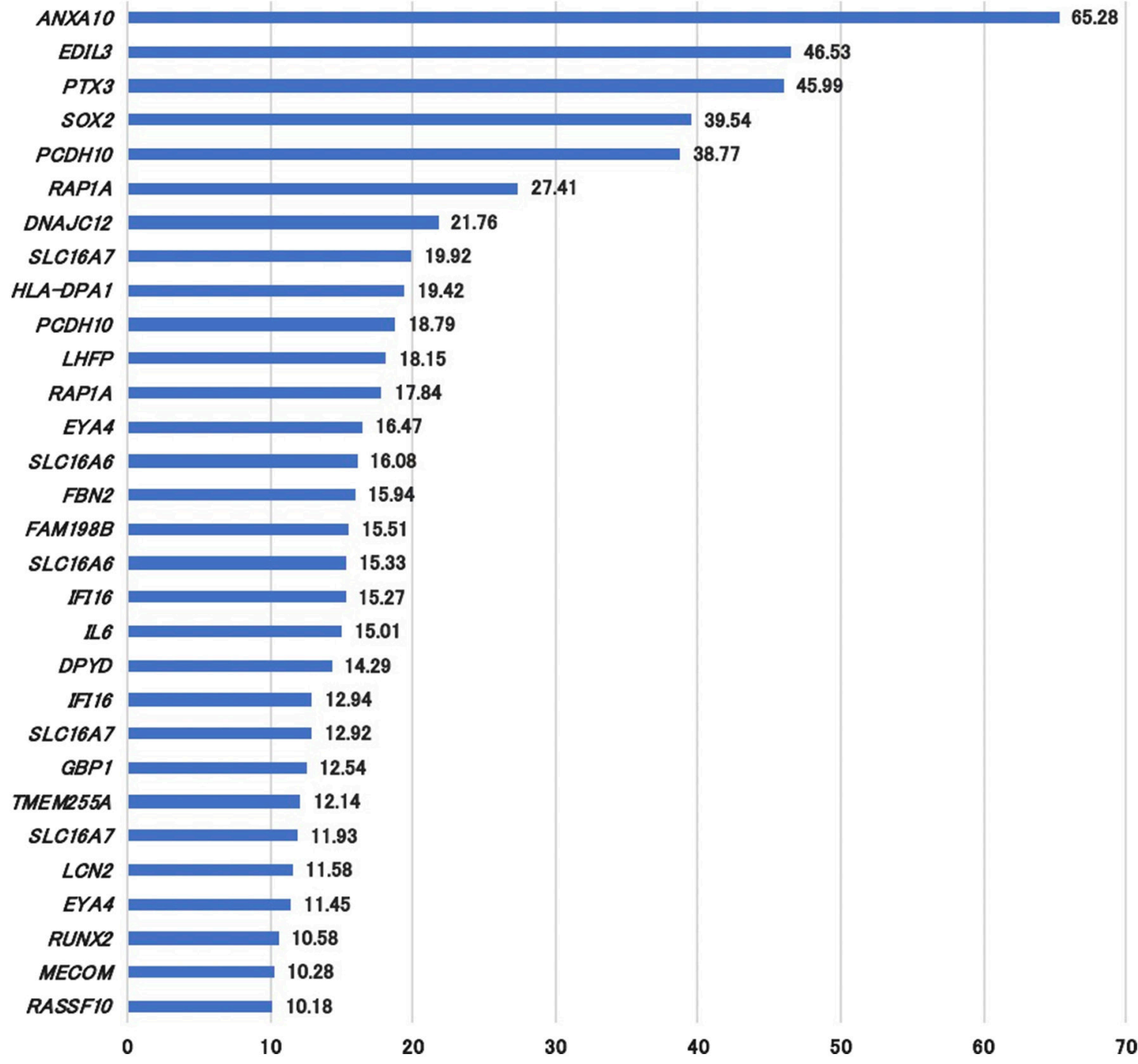

Figure 7. Table of the top 30 genes with high fold change values with microarray analysis. Data are presented as a fold change in relative gene expression between A549 and A549/KL-1 cell lines. KL, Klotho.

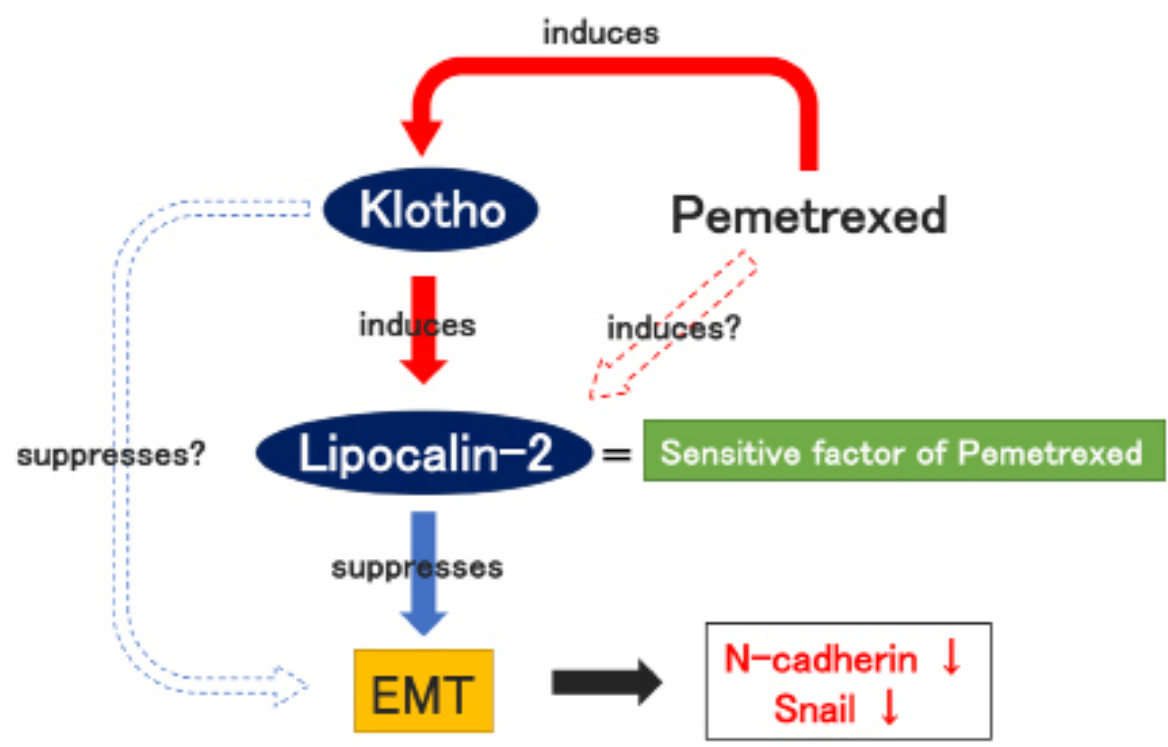

Figure 8. Schematic diagram of the mechanism of action of pemetrexed and the regulation of EMT dependent upon the expression of the Klotho gene. EMT, epithelial mesenchymal transition; Snail, Snail 1. 
in vitro. Feng et al (51) found that LCN2 suppresses proliferation, metastasis/invasion and EMT by attenuating the promoter activity of the NF- $\kappa \mathrm{B}$-dependent activation of Snail. The present study also assessed downregulated genes, but there were no genes that seemed to be involved in EMT or suppression of cadherin.

We therefore hypothesized that the overexpression of Klotho completely suppressed the expression of the mesenchymal markers N-cadherin and Snail through the induction of LCN2, as shown in Fig. 8. Based on the findings of the present study, it seems that Klotho expression does not directly inhibit EMT, but that LCN2 upregulates Klotho by inhibiting EMT. How LCN2 suppresses and modulates N-cadherin and Snail remains unknown and this needs further investigation by future studies.

The induction of Klotho expression by pemetrexed treatment is a very interesting phenomenon. Hence, it was hypothesized in the present study that if Klotho expression is a determinant of pemetrexed sensitivity, pemetrexed may suppress cell proliferation by regulating $\mathrm{N}$-cadherin and Snail through the induction of LCN2. It was reported that microRNA (miR)-761 overexpression reduced the expression of $\mathrm{N}$-cadherin and vimentin, but increased the expression of E-cadherin suggesting inhibition of EMT (52). Tao et al (53) demonstrated that miR-451a serves a significant role in suppressing the drug resistance of lung cancer cells treated with doxorubicin by alleviating the effect on the EMT, as evidenced by marked reductions in the expressions of $\mathrm{N}$-cadherin and vimentin. In addition, Ren et al (54) demonstrated that wild-type p53 suppresses migration, invasion, EMT and stemness in PC-3 cells, at least partially by modulating miR-145.

TS as one of the targets for antifolate drugs was added to the analysis of the present study. Pemetrexed upregulated the expression of TS and this finding was consistent with the results of previous studies (55-57). Although pemetrexed treatment increased the expression of TS in both the A549 and A549/KL-1 cells in the present study, no difference in TS expression was observed between the two cell types. Hence, pemetrexed, which is a folate metabolism antagonist in Klotho-overexpressing cells (44), may activate mechanisms other than those involving TS. The involvement of EMT regulation as a determinant of pemetrexed activity has been less clear, but the involvement of the EMT in resistance has been previously suggested (44). Wu et al (49) demonstrated that pemetrexed caused cell cycle arrest in the G1 phase and S phase of A549 cells, and they noted a high expression of LCN2 proteins in A549 cells after pemetrexed exposure. The aforementioned study concluded that LCN2 can be used as a new biomarker for predicting the responsiveness to pemetrexed (44). Such reports are not inconsistent with the schematic proposed by the present study (Fig. 8).

To the best of our knowledge, this is the first study that found that the Klotho gene was a suppressor of the EMT in lung adenocarcinoma. However, there were several limitations of the present study including that only the A549 cell line was used, how LCN2 suppresses EMT via Klotho overexpression was not clarified and genes downregulated by Klotho expression were not investigated. Hence, further studies are needed to draw more definitive conclusions about the association between Klotho expression and LCN2 and the effect of LCN2 on EMT in lung adenocarcinoma. In addition, how LCN2 suppresses and modulates N-cadherin and Snail also warrants future investigation.

The results of the present study reveal a novel mechanism of action on the antitumor effects of pemetrexed: Namely, the regulation of LCN2-mediated N-cadherin expression. In addition, confirming Klotho expression during cancer treatment may have great potential as a predictor of pemetrexed efficacy and as a component in the selection of personalized medicine for adjuvant chemotherapy in postoperative settings.

\section{Acknowledgements}

Not applicable.

\section{Funding}

This study was supported in part by a Grant-in-Aid for Young Scientists from the Japan Society for the Promotion of Science (JSPS) [KAKENHI grant number, 19K18225 (K.T.)].

\section{Availability of data and materials}

The datasets used and/or analyzed during the current study are available from the corresponding author on reasonable request.

\section{Authors' contributions}

JU conceived and designed the experiments. The experiments were performed by KT. KT, TI, TS, TM and MM provided substantial contributions to the analysis of the data and creation of the figures. JU and KT wrote the manuscript. All authors have read and approved the manuscript.

\section{Ethics approval and consent to participate}

Not applicable.

\section{Patient consent for publication}

Not applicable.

\section{Competing interests}

The authors declare that they have no competing interests.

\section{References}

1. Henley SJ, Thomas CC, Lewis DR, Ward EM, Islami F, Wu M, Weir HK, Scott S, Sherman RL, Ma J, et al: Annual report to the nation on the status of cancer, part II: Progress toward Healthy People 2020 objectives for 4 common cancers. Cancer 126: 2250-2266, 2020.

2. Bodor JN, Kasireddy V and Borghaei H: First-line therapies for metastatic lung adenocarcinoma without a driver mutation. J Oncol Pract 14: 529-535, 2018.

3. Malhotra J, Jabbour SK and Aisner J: Current state of immunotherapy for non-small cell lung cancer. Transl Lung Cancer Res 6: 196-211, 2017.

4. Voong KR, Feliciano J, Becker D and Levy B: Beyond PD-L1 testing-emerging biomarkers for immunotherapy in non-small cell lung cancer. Ann Transl Med 5: 376, 2017. 
5. Chen T, You Y, Jiang H and Wang ZZ: Epithelial-mesenchymal transition (EMT): A biological process in the development, stem cell differentiation, and tumorigenesis. J Cell Physiol 232: 3261-3272, 2017.

6. Gravdal K, Halvorsen OJ, Haukaas SA and Akslen LA: A switch from $\mathrm{E}$-cadherin to $\mathrm{N}$-cadherin expression indicates epithelial to mesenchymal transition and is of strong and independent importance for the progress of prostate cancer. Clin Cancer Res 13: 7003-7011, 2007.

7. Kahlert C, Lahes S, Radhakrishnan P, Dutta S, Mogler C, Herpel E, Brand K, Steinert G, Schneider M, Mollenhauer M, et al: Overexpression of ZEB2 at the invasion front of colorectal cancer is an independent prognostic marker and regulates tumor invasion in vitro. Clin Cancer Res 17: 7654-7663, 2011.

8. Chen Q, Yang W, Wang X, Li X, Qi S, Zhang Y and Gao MQ: TGF- $\beta 1$ Induces EMT in bovine mammary epithelial cells through the TGF $\beta 1 /$ smad signaling pathway. Cell Physiol Biochem 43: 82-93, 2017.

9. Jager T, Becker M, Eisenhardt A, Tilki D, Tötsch M, Schmid KW, Romics I, Rübben H, Ergün S and Szarvas T: The prognostic value of cadherin switch in bladder cancer. Oncol Rep 23: 1125-1132, 2010.

10. Fischer KR, Durrans A, Lee S, Sheng J, Li F, Wong ST, Choi H, El Rayes T, Ryu S, Troeger J, et al: Epithelial-to-mesenchymal transition is not required for lung metastasis but contributes to chemoresistance. Nature 527: 472-476, 2015.

11. Ryu HS, Park DJ, Kim HH, Kim WH and Lee HS: Combination of epithelial-mesenchymal transition and cancer stem cell-like phenotypes has independent prognostic value in gastric cancer. Hum Pathol 43: 520-528, 2012.

12. Ye X, Brabletz T, Kang Y, Longmore GD, Nieto MA, Stanger BZ, Yang $\mathrm{J}$ and Weinberg RA: Upholding a role for EMT in breast cancer metastasis. Nature 547: E1-E3, 2017.

13. Ye X, Tam WL, Shibue T, Kaygusuz Y, Reinhardt F, Ng Eaton E and Weinberg RA: Distinct EMT programs control norma mammary stem cells and tumour-initiating cells. Nature 525: 256-260, 2015.

14. Nieto MA, Huang RY, Jackson RA and Thiery JP: EMT: 2016 Cell 166: 21-45, 2016.

15. Terry S, Buart S, Tan TZ, Gros G, Noman MZ, Lorens JB, Mami-Chouaib F, Thiery JP and Chouaib S: Acquisition of tumor cell phenotypic diversity along the EMT spectrum under hypoxic pressure: Consequences on susceptibility to cell-mediated cytotoxicity. Oncoimmunology 6: e1271858, 2017.

16. Xu X, Zhang L, He X, Zhang P, Sun C, Xu X, Lu Y and Li F: TGF- $\beta$ plays a vital role in triple-negative breast cancer (TNBC) drug-resistance through regulating stemness, EMT and apoptosis. Biochem Biophys Res Commun 502: 160-165, 2018.

17. Tan TZ, Miow QH, Miki Y, Noda T, Mori S, Huang RY and Thiery JP: Epithelial-mesenchymal transition spectrum quantification and its efficacy in deciphering survival and drug responses of cancer patients. EMBO Mol Med 6: 1279-1293, 2014

18. Shah PP, Dupre TV, Siskind LJ and Beverly LJ: Common cytotoxic chemotherapeutics induce epithelial-mesenchymal transition (EMT) downstream of ER stress. Oncotarget 8 : 22625-22639, 2017.

19. Kuro-o M, Matsumura Y, Aizawa H, Kawaguchi H, Suga T, Utsugi T, Ohyama Y, Kurabayashi M, Kaname T, Kume E, et al: Mutation of the mouse klotho gene leads to a syndrome resembling ageing. Nature 390: 45-51, 1997.

20. Matsumura Y, Aizawa H, Shiraki-Iida T, Nagai R, Kuro-o M and Nabeshima Y: Identification of the human klotho gene and its two transcripts encoding membrane and secreted klotho protein. Biochem Biophys Res Commun 242: 626-630, 1998.

21. Kurosu H, Yamamoto M, Clark JD, Pastor JV, Nandi A, Gurnani P, McGuinness OP, Chikuda H, Yamaguchi M, Kawaguchi H, et al: Suppression of aging in mice by the hormone Klotho. Science 309: 1829-1833, 2005.

22. Rubinek T and Wolf I: The role of alpha-klotho as a universal tumor suppressor. Vitam Horm 101: 197-214, 2016

23. Delcroix V, Mauduit O, Tessier N, Montillaud A, Lesluyes T, Ducret T, Chibon F, Van Coppenolle F, Ducreux S and Vacher P: The role of the anti-aging protein klotho in IGF-1 signaling and reticular calcium leak: Impact on the chemosensitivity of dedifferentiated liposarcomas. Cancers (Basel) 10: 439, 2018

24. Wolf I, Levanon-Cohen S, Bose S, Ligumsky H, Sredni B, Kanety H, Kuro-o M, Karlan B, Kaufman B, Koeffler HP and Rubinek T: Klotho: A tumor suppressor and a modulator of the IGF-1 and FGF pathways in human breast cancer. Oncogene 27: 7094-7105, 2008.
25. Xie B, Chen J, Liu B and Zhan J: Klotho acts as a tumor suppressor in cancers. Pathol Oncol Res 19: 611-617, 2013.

26. Wolf I, Laitman Y, Rubinek T, Abramovitz L, Novikov I, Beeri R, Kuro-O M, Koeffler HP, Catane R, Freedman LS, et al: Functional variant of KLOTHO: A breast cancer risk modifier among BRCA1 mutation carriers of Ashkenazi origin. Oncogene 29: 26-33, 2010.

27. Zhang J, Cao K, Pastor JV, Li L, Moe OW and Hsia CCW Alpha-Klotho, a critical protein for lung health, is not expressed in normal lung. FASEB Bioadv 1: 675-687, 2019.

28. Usuda J, Ichinose S, Ishizumi T, Ohtani K, Inoue T, Saji H, Kakihana M, Kajiwara N, Uchida O, Nomura M, et al: Klotho predicts good clinical outcome in patients with limited-disease small cell lung cancer who received surgery. Lung Cancer 74: 332-337, 2011.

29. Usuda J, Ichinose S, Ishizumi T, Ohtani K, Inoue T, Saji H, Kakihana M, Kajiwara N, Uchida O, Nomura M, et al: Klotho is a novel biomarker for good survival in resected large cell neuroendocrine carcinoma of the lung. Lung Cancer 72: 355-359, 2011.

30. Ibi T, Usuda J, Inoue T, Sato A and Takegahara K: Klotho expression is correlated to molecules associated with epithelial-mesenchymal transition in lung squamous cell carcinoma. Oncol Lett 14: 5526-5532, 2017.

31. Rollins KD and Lindley C: Pemetrexed: A multitargeted antifolate. Clin Ther 27: 1343-1382, 2005.

32. Liang SQ, Marti TM, Dorn P, Froment L, Hall SR, Berezowska S, Kocher G, Schmid RA and Peng RW: Blocking the epithelial-to-mesenchymal transition pathway abrogates resistance to anti-folate chemotherapy in lung cancer. Cell Death Dis 195: e1824, 2015.

33. Buckley AF and Kakar S: Comparison of the Dako EGFR pharmDx kit and Zymed EGFR antibody for assessment of EGFR status in colorectal adenocarcinoma. Appl Immunohistochem Mol Morphol 15: 305-309, 2007.

34. Usuda J, Azizuddin K, Chiu SM and Oleinick NL: Association between the photodynamic loss of $\mathrm{Bcl}-2$ and the sensitivity to apoptosis caused by phthalocyanine photodynamic therapy. Photochem Photobiol 78: 1-8, 2003.

35. Maehara $\mathrm{S}$, Usuda J, Ishizumi $\mathrm{T}$, Ichinose $\mathrm{S}$, Ohtani $\mathrm{K}$, Inoue $\mathrm{T}$, Imai K, Furumoto H, Kudo Y, Kajiwara N, et al: Combination effect of photodynamic therapy using NPe6 with pemetrexed for human malignant pleural mesothelioma cells. Int J Oncol 46: 741-749, 2015.

36. Booth L, Roberts JL, Tavallai M, Chuckalovcak J, Stringer DK, Koromilas AE, Boone DL, McGuire WP, Poklepovic A and Dent P: [Pemetrexed + Sorafenib] lethality is increased by inhibition of ERBB1/2/3-PI3K-NFкB compensatory survival signaling. Oncotarget 7: 23608-23632, 2016.

37. Takahashi A, Seike M, Chiba M, Takahashi S, Nakamichi S, Matsumoto M, Takeuchi S, Minegishi Y, Noro R, Kunugi S, et al: Ankyrin repeat domain 1 overexpression is associated with common resistance to afatinib and osimertinib in EGFR-mutant lung cancer. Sci Rep 8: 14896, 2018.

38. Nakamichi S, Seike M, Miyanaga A, Chiba M, Zou F, Takahashi A, Ishikawa A, Kunugi S, Noro R, Kubota $\mathrm{K}$ and Gemma A: Overcoming drug-tolerant cancer cell subpopulations showing AXL activation and epithelial-mesenchymal transition is critical in conquering ALK-positive lung cancer. Oncotarget 9: 27242-27255, 2018.

39. Noro R, Miyanaga A, Minegishi Y, Okano T, Seike M, Soeno C, Kataoka K, Matsuda K, Yoshimura A and Gemma A: Histone deacetylase inhibitor enhances sensitivity of non-small-cell lung cancer cells to 5-FU/S-1 via down-regulation of thymidylate synthase expression and up-regulation of $\mathrm{p} 21^{\text {waf } 1 / \mathrm{cip} 1}$ expression. Cancer Sci 101: 1424-1430, 2010.

40. Herbst RS, Morgensztern D and Boshoff C: The biology and management of non-small cell lung cancer. Nature 553: 446-454, 2018.

41. Giovannetti E, Lemos C, Tekle C, Smid K, Nannizzi S, Rodriguez JA, Ricciardi S, Danesi R, Giaccone G and Peters GJ: Molecular mechanisms underlying the synergistic interaction of erlotinib, an epidermal growth factor receptor tyrosine kinase inhibitor, with the multitargeted antifolate pemetrexed in non-small-cell lung cancer cells. Mol Pharmacol 73: 1290-1300, 2008.

42. Folwaczny M, Karnesi E, Berger T and Paschos E: Clinical association between chronic periodontitis and the leukocyte extravasation inhibitors developmental endothelial locus-1 and pentraxin-3. Eur J Oral Sci 125: 258-264, 2017. 
43. Kamal Y, Schmit SL, Hoehn HJ, Amos CI and Frost HR Transcriptomic differences between primary colorectal adenocarcinomas and distant metastases reveal metastatic colorectal cancer subtypes. Cancer Res 79: 4227-4241, 2019.

44. Fernandez-Garcia CE, Roldan-Montero R, Tarin C, Martinez-Lopez D, Pastor-Vargas C, Blanco-Colio LM and Martín-Ventura JL: Lipocalin-2, a potential therapeutic target in advanced atherosclerosis. Atherosclerosis 278: 321-322, 2018.

45. Doi S, Zou Y, Togao O, Pastor JV, John GB, Wang L, Shiizaki K, Gotschall R, Schiavi S, Yorioka N, et al: Klotho inhibits transforming growth factor-beta1 (TGF-beta1) signaling and suppresses renal fibrosis and cancer metastasis in mice. J Biol Chem 286: 8655-8665, 2011.

46. Marques da Fonseca L, Jacques da Silva LR, Santos Dos Reis J, Rodrigues da Costa Santos MA, de Sousa Chaves V, Monteiro da Costa K, Sa-Diniz JN, Freire de Lima CG, Morrot A, Nunes Franklim T, et al: Piperine inhibits TGF- $\beta$ signaling pathways and disrupts EMT-related events in human lung adenocarcinoma cells. Medicines (Basel) 7: 19, 2020

47. Chen B, Ma X, Liu S, Zhao W and Wu J: Inhibition of lung cancer cells growth, motility and induction of apoptosis by Klotho, a novel secreted Wnt antagonist, in a dose-dependent manner. Cancer Biol Ther 13: 1221-1228, 2012.

48. Xu D, Yuan H, Meng Z, Yang C, Li Z, Li M, Zhang Z, Gan Y and Tu H: Cadherin 13 inhibits pancreatic cancer progression and epithelial-mesenchymal transition by Wnt/ $\beta$-catenin signaling. J Cancer 11: 2101-2112, 2020.

49. Wu MF, Hsiao YM, Huang CF, Huang YH, Yang WJ, Chan HW, Chang JT and Ko JL: Genetic determinants of pemetrexed responsiveness and nonresponsiveness in non-small cell lung cancer cells. J Thorac Oncol 5: 1143-1151, 2010.

50. Wang YP, Yu GR, Lee MJ,Lee SY, Chu IS, Leem SH and Kim DG: Lipocalin-2 negatively modulates the epithelial-to-mesenchymal transition in hepatocellular carcinoma through the epidermal growth factor (TGF-beta1)/Lcn2/Twist1 pathway. Hepatology 58 : 1349-1361, 2013
51. Feng M, Feng J, Chen W, Wang W, Wu X, Zhang J, Xu F and Lai M: Lipocalin2 suppresses metastasis of colorectal cancer by attenuating NF- $\kappa \mathrm{B}$-dependent activation of snail and epithelial mesenchymal transition. Mol Cancer 15: 77, 2016.

52. Cheng J, Chen J, Zhao Y, Yang J, Xue K and Wang Z: MicroRNA-761 suppresses remodeling of nasal mucosa and epithelial-mesenchymal transition in mice with chronic rhinosinusitis through LCN2. Stem Cell Res Ther 11: 151, 2020.

53. Tao L, Shu-Ling W, Jing-Bo $H$, Ying $Z$, Rong $H$, Xiang-Qun L, Wen-Jie C and Lin-Fu Z: MiR-451a attenuates doxorubicin resistance in lung cancer via suppressing epithelialmesenchymal transition (EMT) through targeting c-Myc. Biomed Pharmacother 125: 109962, 2020.

54. Ren D, Wang M, Guo W, Zhao X, Tu X, Huang S, Zou X and Peng X: Wild-type p53 suppresses the epithelial-mesenchymal transition and stemness in PC-3 prostate cancer cells by modulating miR145. Int J Oncol 42: 1473-1481, 2013.

55. Kuo WT, Tu DG, Chiu LY, Sheu GT and Wu MF: High pemetrexed sensitivity of docetaxel-resistant A549 cells is mediated by TP53 status and downregulated thymidylate synthase. Oncol Rep 38: 2787-2795, 2017.

56. Chiu LY, Hsin IL, Yang TY, Sung WW, Chi JY, Chang JT, Ko JL and Sheu GT: The ERK-ZEB1 pathway mediates epithelial-mesenchymal transition in pemetrexed resistant lung cancer cells with suppression by vinca alkaloids. Oncogene 36: 242-253, 2017.

57. Yoon JY, Park CK, Choi YD, Oh IJ and Kim YC: Predictive factors for long-term responders of pemetrexed maintenance treatment in non-small cell lung cancer. Thorac Cancer 10: 942-949, 2019.

(i) $\Theta$ This work is licensed under a Creative Commons cc Attribution-NonCommercial-NoDerivatives 4.0 International (CC BY-NC-ND 4.0) License. 